23.7 months; $\mathrm{P}=0.014)$. In multivariate analysis adjusting for confounders, a duration of $\geq 30 \mathrm{~min}$ of MAP under 65 $\mathrm{mmHg}$ was identified as an independent poor prognostic factor for PFS (adjusted HR, 1.376; 95\% CI, 1.035-1.830; $\mathrm{P}=0.028)$. Shorter PFS was observed in the group with a MDPE <4.0\% (adjusted HR, 1.351; 95\% CI, 1.024-1.783; $\mathrm{P}=0.033$ ) and a wobble $\geq 7.5 \%$ (adjusted HR, 1.445; 95\% CI, 1.100-1.899; $\mathrm{P}=0.008)$. However, no differences were observed in overall survival.

Conclusions The three intraoperative variables for hemodynamic instability, cumulative duration of MAP $<65 \mathrm{mmHg}$, MDPE, and wobble, might be novel prognostic biomarkers for disease recurrence in patients with HGSOC.

\section{EPV211/\#493 INCOMPLETE CYCLES OF CHEMOTHERAPY USING WEEKLY GEMCITABINE AFFECTING PROGNOSIS OF PLATINUM-RESISTANT OVARIAN CANCER}

${ }^{1}$ A Seol ${ }^{*},{ }^{2}$ SJ Park, ${ }^{1} E J$ Lee, ${ }^{1} \mathrm{M}$ Lee, ${ }^{1} \mathrm{HS}$ Kim, ${ }^{1} \mathrm{HH}$ Chung, ${ }^{1} \mathrm{~J}$-W Kim, ${ }^{1} \mathrm{NH}$ Park, ${ }^{1} \mathrm{Y}$-S Song. ${ }^{1}$ Seoul National University College of Medicine, Department of Obstetrics and Gynecology, Seoul, Korea, Republic of; ${ }^{2}$ Seoul National University College of Medicine, Obstetrics and Gynecology, Seoul, Korea, Republic of

\subsection{6/ijgc-2021-IGCS.282}

Objectives To evaluate the risk of incomplete cycles of weekly gemcitabine on survival for patients with platinum-resistant ovarian cancer (PROC).

Methods We collected patients with PROC who received weekly gemcitabine $(1000 \mathrm{mg} / \mathrm{m} 2$; D1, D8 every 3 weeks or D1, D8, D15 every 4 weeks) between 2006-2018. We investigated rates of completed cycles, skipped cycles, dose reduction (DR) and prophylactic granulocyte colony-stimulating factor (G-CSF) usage, tumor response and factors affecting progression-free survival (PFS) and overall survival (OS).

Results A total of 101 patients with PROC received weekly gemcitabine. 58(57.4\%) completed scheduled cycles without skip and $86(85.1 \%)$ completed more than $80 \%$ of scheduled cycles. DR and the use of G-CSF were observed in 34(33.7\%) and 25 patients $(24.8 \%)$, respectively. Weekly gemcitabine was skipped because of grade3 or more hematologic toxicity (31.7\%). Complete response, partial response, stable disease and progressive disease were identified in $1(1 \%), 12(11.9 \%)$, $26(25.7 \%)$ and $61(60.4 \%)$. In terms of survival, the completion rate of scheduled cycles $\geq 80 \%$ was a factor for better OS (median OS, the completion rate of scheduled cycles $\geq 80 \%$ vs. $<80 \%$, 39.23 months vs. 8.97months, $\mathrm{p}=0.011$ ), but not for better PFS (median PFS, the completion rate of scheduled cycles $\geq 80 \% \quad$ vs. $\quad<80 \%, \quad 2.89$ months vs. 2.43 months, $\mathrm{p}=0.238$ ). Use of G-CSF was factor for better PFS and OS (median PFS, G-CSF group vs. non-G-CSF group, 2.53 month vs. 2.07 month, $\mathrm{p}=0.023$; median OS, 39.23 months vs. 14.72months, $\mathrm{p}=0.011$ )

Conclusions Incompletion of scheduled cycles of weekly gemcitabine may be associated with prognosis, and especially, the completion rate of scheduled cycles $<80 \%$ may not improve survival in patients with PROC.

\section{EPV212/\#496 SURVIVAL IMPACT OF INTERNAL MAMMARY OR SUPRACLAVICULAR LYMPHADENECTOMY ON STAGE IVB OVARIAN CANCER WITH SUPRADIAPHRAGMATIC LYMPH NODE METASTASIS}

${ }^{1}$ SJ Park*, ${ }^{2} \mathrm{M}$ Lee, ${ }^{2} \mathrm{HH}$ Chung, ${ }^{1} \mathrm{~J}-\mathrm{W}$ Kim, ${ }^{2} \mathrm{NH}$ Park, ${ }^{2}$-S Song, ${ }^{3} \mathrm{~S}$ Park, ${ }^{4} \mathrm{HS}$ Kim. ${ }^{1}$ Seoul National University College of Medicine, Obstetrics and Gynecology, Seoul, Korea, Republic of; ${ }^{2}$ Seoul National University College of Medicine, Department of Obstetrics and Gynecology, Seoul, Korea, Republic of; ${ }^{3}$ Seoul National University Hospital, Department of Thoracic and Cardiovascular Surgery, Seoul, Korea, Republic of; ${ }^{4}$ Seoul National University Hospital, Department of Obstetrics and Gynecology, Seoul, Korea, Republic of

\subsection{6/ijgc-2021-IGCS.283}

Objectives To evaluate the survival impact of extensive lymphadenectomy as part of debulking surgery in stage IVB ovarian cancer with supradiaphragmatic lymph node metastasis.

Methods We retrospectively enrolled patients with stage IVB ovarian cancer who had $5 \mathrm{~mm}$ or larger lymph nodes in the supradiaphragmatic area including cardiophrenic, internal mammary and supraclavicular lymph nodes on computed tomography (CT) between January 2010 and January 2020, which were resectable evaluated by thoracic surgeon. Optimal debulking surgery (ODS) was defined as residual disease less than $5 \mathrm{~mm}$ in both abdominal and thoracic cavities, and suboptimal debulking surgery (SDS) was defined as residual disease more than $5 \mathrm{~mm}$ in abdominal or thoracic cavities.

Results A total of 121 patients underwent primary debulking surgery (PDS, $\mathrm{n}=68)$ and interval debulking surgery after neoadjuvant chemotherapy (IDS, $n=53$ ). Patients who underwent ODS showed better progression-free survival (PFS) than those who underwent SDS during PDS (median, 23.7 vs. 14.1 mons; $p=0.035$ ) despite no difference of PFS between ODS and SDS in those treated with IDS. Moreover, internal mammary or supraclavicular lymphadenectomy, bevacizumab administration and abdominal optimal cytoreduction were favorable factors for PFS in patients who underwent PDS (adjusted hazard ratios, $0.169,0.185,0.154 ; 95 \%$ confidence intervals, $0.059-0.484,0.061-0.557,0.043-0.550 ; \mathrm{p}=0.001,0.003$, 0.004) despite no factors affecting PFS in those treated with IDS.

Conclusions Internal mammary or supraclavicular lymphadenectomy for ODS during PDS may have the potential to improve PFS in patients with stage IVB ovarian cancer with supradiaphragmatic lymph node metastasis.

\section{EPV213/\#503 PLATINUM -SENSITIVE OR RESISTANT RELAPSED OVARIAN CANCER: WHICH PREDICTIVE FACTORS?}

${ }^{1} \mathrm{Y}$ Berrazaga*, ${ }^{1} \mathrm{~N}$ Mejri, ${ }^{1} \mathrm{H}$ Rachdi, ${ }^{2} \mathrm{M}$ Ferjaoui, ${ }^{3} \mathrm{R}$ Arfaoui, ${ }^{1} \mathrm{~N}$ Daoud, ${ }^{1} \mathrm{H}$ Boussen. ${ }^{1}$ Abdrahman Mami hospital medical oncology department Tunisia, Medical Oncology, Ariana, Tunisia; ${ }^{2}$ maternity and neonatal center of Tunis, B, Tunis, Tunisia; ${ }^{3}$ Tunis military hospital, Department of Gynecology and Obstetrics, Tunis, Tunisia

\subsection{6/ijgc-2021-IGCS.284}

Objectives The platinum-free interval (PFI) in epithelial ovarian cancer is a major factor that guides the management and predicts prognosis of the disease. We aimed to study predictive 